\title{
A study about energy consumption and cutting fluid used to clutch case machining
}

\author{
Henri-François Boyer ${ }^{1, a}$, Jeremy Waremme ${ }^{2}$, Jean-Luc Bourdiol ${ }^{3}$ \\ AND DAVID DELAUNAY ${ }^{4}$ \\ 1 Renault SA, Direction de l'Ingénierie Mécanique, 67 rue des Bons Raisins, 92508 Rueil-Malmaison Cedex, France \\ Laboratoire Procédés et Ingénieries en Mécanique et Matériaux, Arts et Métiers ParisTech, 151 Bd de l'Hôpital, \\ 75013 Paris, France \\ 2 École Nationale Supérieure de Mécanique et des Microtechniques (ENSMM), 26 chemin de l'Épitaphe, \\ 25030 Besançon Cedex, France \\ 3 COMAU France, ZI de Mélou, rue de l'Industrie, 81100 Castres, France \\ 4 Renault SA, Département Ingénierie Process Cléon, Usine de Cléon, BP 105, 76410 Cléon, France
}

Received 2 February 2011, Accepted 27 June 2011

\begin{abstract}
This paper deals with a balance of energy and cutting fluid consumption used to manufacture an aluminum clutch case (AlSi9Cu3 $(\mathrm{Fe})$ ) in industrial context. To establish this balance sheet constitutes the first stage of a reflection aiming at reducing the economic and ecological impact of the production of mechanical parts. Indeed, before intending to set up new technologies susceptible to reduce the cost of manufacturing of a part it is necessary to draw up an inventory of fixtures of the current situation. This paper brings to light the energy and environmental cost connected to the use of cutting fluids in machining. It establishes a prerequisite in the studies necessary for the implementation of a new technology (the minimum quantity lubrication or MQL) and in the characterization of this technology in comparison with the existing (wet machining). This study joins within the framework of a project supported by the "agence de l'environnement et de la maîtrise de l'énergie" (ADEME, France).
\end{abstract}

Key words: Wet machining / energy / environment / minimum quantity lubrication / MQL

Résumé - Étude de la consommation d'énergie et de liquide de coupe nécessaires à l'usinage d'un carter d'embrayage aluminium. Cet article s'intéresse à établir un bilan de la consommation d'énergie et de liquide de coupe nécessaire à la production d'un carter d'embrayage aluminium $(\mathrm{AlSi} 9 \mathrm{Cu} 3(\mathrm{Fe}))$ en contexte industriel (usinage en très grande série). Établir ce bilan constitue la première étape d'une réflexion ayant pour but de réduire l'impact économique et écologique de la production de pièces mécaniques. En effet, avant d'envisager de mettre en place de nouvelles technologies susceptibles de réduire le coût d'usinage d'une pièce, il est nécessaire de dresser un état des lieux de la situation actuelle. Cet article met en évidence le coût énergétique et environnemental lié à l'utilisation de fluides de coupe en usinage. Il constitue ainsi un préalable aux études nécessaires à la mise en place d'une nouvelle technologie (la micro lubrification ou MQL) et à la caractérisation de cette technologie en comparaison avec l'existant (usinage avec arrosage). Cette étude s'inscrit dans le cadre d'un projet soutenu par l'agence de l'environnement et de la maîtrise de l'energie (ADEME, France).

Mots clés : Usinage avec arrosage / énergie / environnement / micro lubrification / MQL

\section{Introduction}

At the moment, the energy and environmental cost of the manufacturing of a mechanical part is a parameter more and more taken into account in the industry. The

\footnotetext{
a Corresponding author:

henri-francois. boyer@renault.com
}

context makes that manufactuters are more and more interested in the ecological impact of their factories and try to reduce, for ecological but also economic reasons, the consumption of natural resources needed for their productions.

This paper deals with the realization of a balance sheet of the energy spent on the manufacturing of an aluminum clutch case as well as in the consumption of cutting fluid 


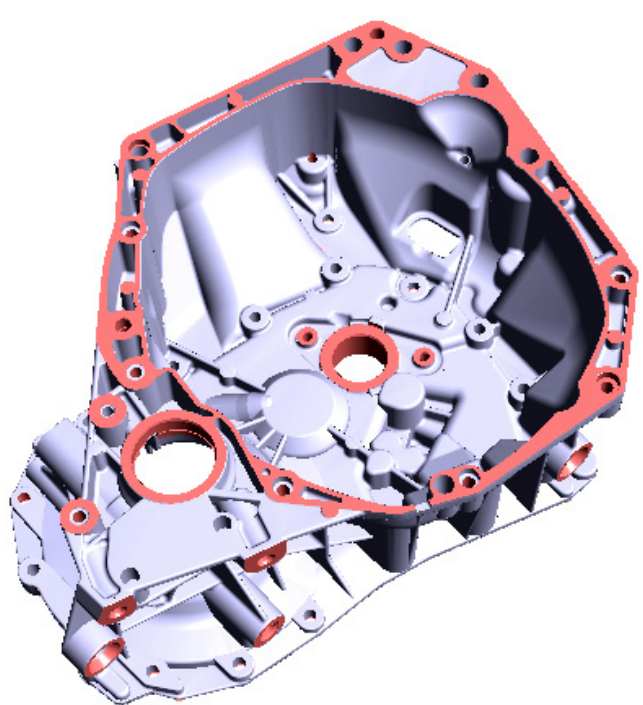

Fig. 1. Aluminium clutch case (Renault SA).

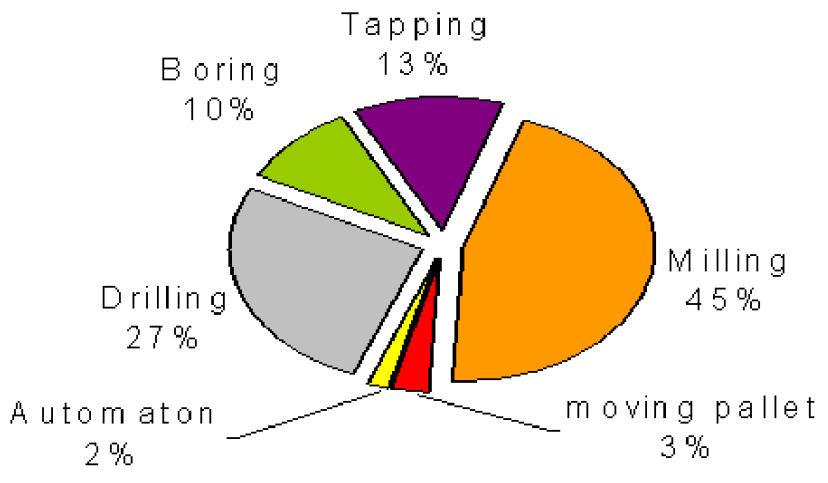

Fig. 2. Distribution of the cycle time by type of operation.

(oil and water) and of compressed air during phases of manufacturing.

\section{Definition of the scope of measure}

Measures presented below were realized in the production plant Renault of Cléon (France). Machinings were realized on Urane 25 of the company COMAU (machine 4 axes palletized). The produced part is a clutch case (Fig. 1) in aluminum alloy $(\mathrm{Al} \mathrm{Si9Cu3} \mathrm{(Fe)).}$

The part is realized in two successive fittings, 28 different tools (which one used on both fittings) are necessary for its complete manufacturing (20 tools for the first one fitting, 9 for the second). The cycle time of the manufacturing is of $6 \mathrm{~min} 12 \mathrm{~s}$. We shall note that this measured cycle time is upper than cycle time really observed on the production line because of time necessities in the recording by the automaton of information during the manufacturing (time reporting at the end of every use of tool). Figure 2 presents the distribution of the time of manufacturing on the part according to the realized type of operation.

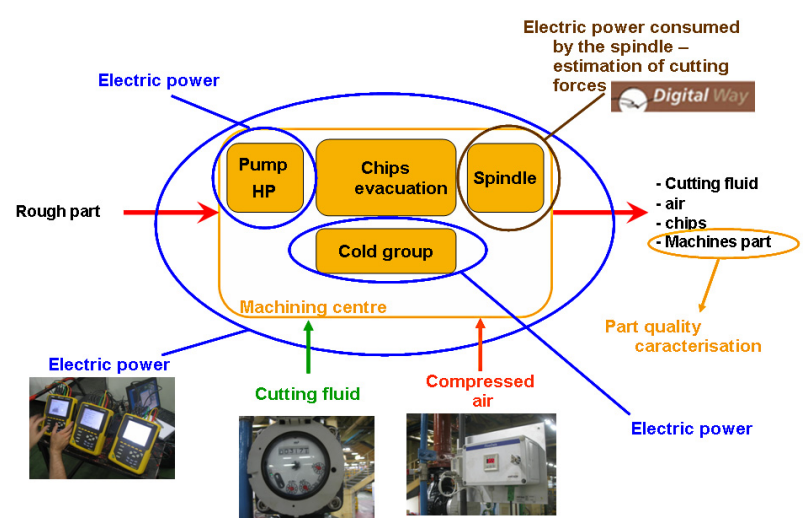

Fig. 3. Perimeter of measurement used on machining center.

\section{Measures realized on the machining centre}

Figure 3 presents the perimeter of measure used on the machining centre.

Four types of electric measures are realized: the instantaneous power consumed by the complete machining centre, the instantaneous power consumed by the spindle, by the pump high pressure (necessary for the rise in pressure of the cutting fluid) and by the cold group of the machine (cooling of the engines of axes and the spindle). It was chosen to be interested in these elements to understand their respective influence on the global consumption of the machine. The various measures of power were simultaneously realized by means of wattmeter.

In parallel, measures of the consumption of compressed air and the volume of cutting fluid which have circulated in the machining centre are made.

\subsection{Electricity}

\subsubsection{General consumption}

Figure 4 presents the instantaneous power consumed by the machining centre according to time for the realization of a crankcase of clutch. The points of negative power correspond to the dismissal of electrical energy on the network of supply during braking of the spindle (machine with ecological conception).

The manufacturing of a crankcase thus requires an energy of $1.52 \mathrm{~kW}$.h. This energy corresponds only in the time of manufacturing of the machine and does not take into account the phases during which the machine is in wait, in stoking, ...

\subsubsection{Consumption of the spindle}

Figure 5 presents the energy consumption of the spindle. This consummate energy is directly connected to the manufacturing and translates the efforts needed for cutting the aluminum. The peaks of power correspond to starts and stops of the spindle.

The spindle consumes an energy of $0.36 \mathrm{~kW}$.h. It represents approximately the fifth of the energy consumed by the machine. 


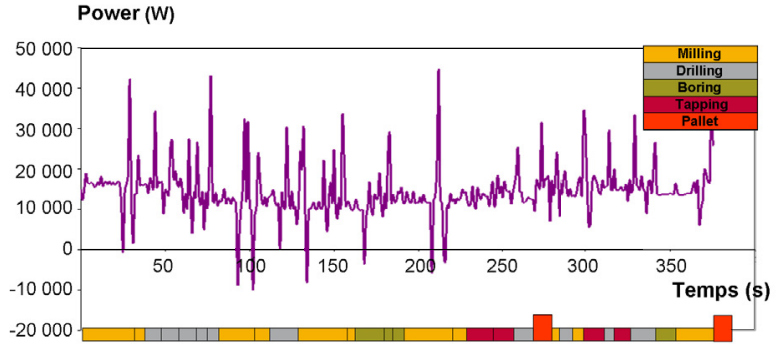

Fig. 4. Power consumed by the machining centre according to time.

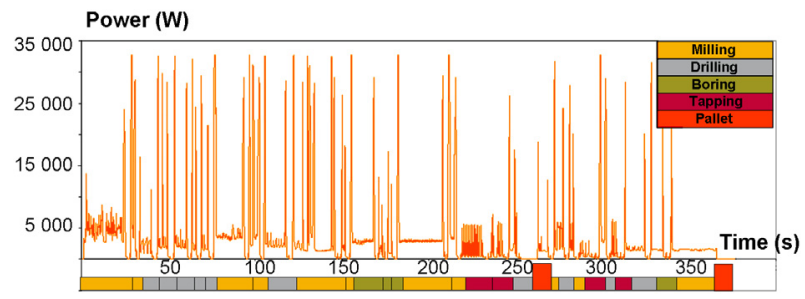

Fig. 5. Power consumed by the spindle of the machining centre according to time (does not take into account returns of energies evoked in Sect. 3.1.1).

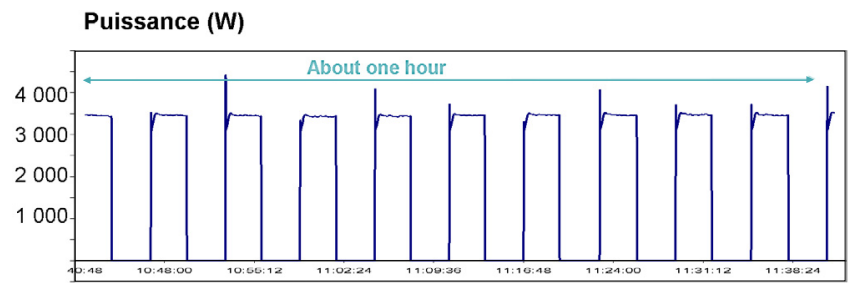

Fig. 6. Power consumed by cold group of the machining centre according to time.

\subsubsection{Consumption of the cold group}

The cold group aims at maintaining in temperature the components of the machine (engines of axes and spindle). It includes two main consumers: the pump of circulation and the group of fluid conditioning.

The instantaneous power consumed by the pump of the cold group is constant during all the duration of manufacturing of the part. It represents a power about $3850 \mathrm{~W}$, that is an energy about $0.4 \mathrm{~kW}$.h by produced part.

Figure 6 presents the consumption of fluid conditioning according to time during one hour of manufacturing. The ignition and the stop of the group of air conditioning is not directly connected to the manufacturing, it depends on the temperature outside of the workshop $\left(22{ }^{\circ} \mathrm{C}\right.$ the day of the measures), of the request of the engines of movement of the machine and the request of the spindle.

For one hour of manufacturing, the group of air conditioning consumes approximately $1.7 \mathrm{~kW} . \mathrm{h}$, that is an energy considered of $0.18 \mathrm{~kW} . \mathrm{h}$ by part.

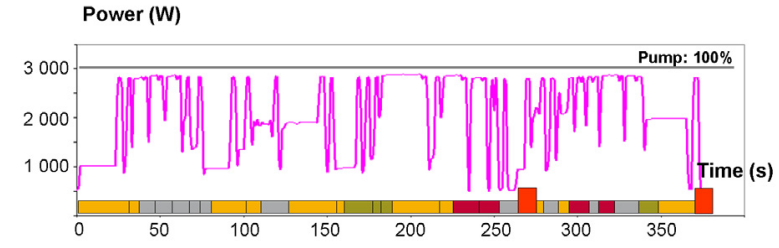

Fig. 7. Power consumed by the high pressure pump according to time.

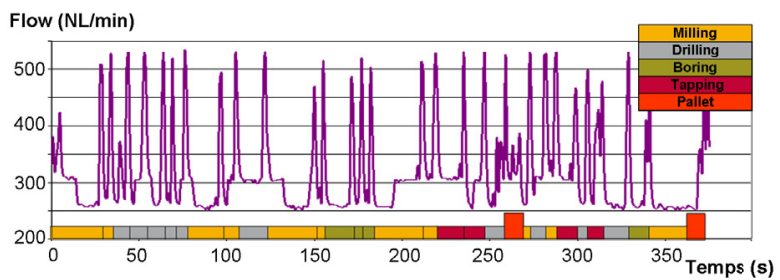

Fig. 8. Instantaneous flox of compressed air.

\subsubsection{Consumption of the high pressure pump}

Figure 7 presents the electric consumption of the high pressure pump (HP pump) according to time for the manufacturing of a clutch case. We notice that for of numerous manufacturing pumps high pressure works in $100 \%$ of its capacity.

During the manufacturing of a clutch case, the HP pump consumes an energy of $0.21 \mathrm{~kW} . \mathrm{h}$.

\subsection{Compressed air}

The flow of compressed air consumed in the course of manufacturing is measured by means of a flowmeter placed in entry of the machine. Figure 8 gives the evolution of the consumption of compressed air during the complete manufacturing of a clutch case.

The compressed air is used for the lubrication under pressure of the rails of movement and the spindle of the machine as well as to realize the blowing of chips.

The pressure of air in entrance of the machine is 4.7 bars. The peaks of consumption observed on the curve correspond to the blowing of the cone of stake in position of the tool in the spindle during the change of tool. This blowing aims at avoiding the presence of chips on the cone of stake in position.

The production of a clutch case requires approximately $2 \mathrm{~m}^{3}$ of air. A study interns Renault allowed to determine the energy cost of production of compressed air: $0.1 \mathrm{~kW} . h . N . \mathrm{m}^{2}$. The energy necessary for the production of compressed air for the realization of a case is thus about $0.23 \mathrm{k}$.W.h.

\subsection{Cutting fluid}

Cutting fluid is used for three offices: grease the interface between tool and part and the interface between tool and chip, evacuate chips (at the same time) of the zone 


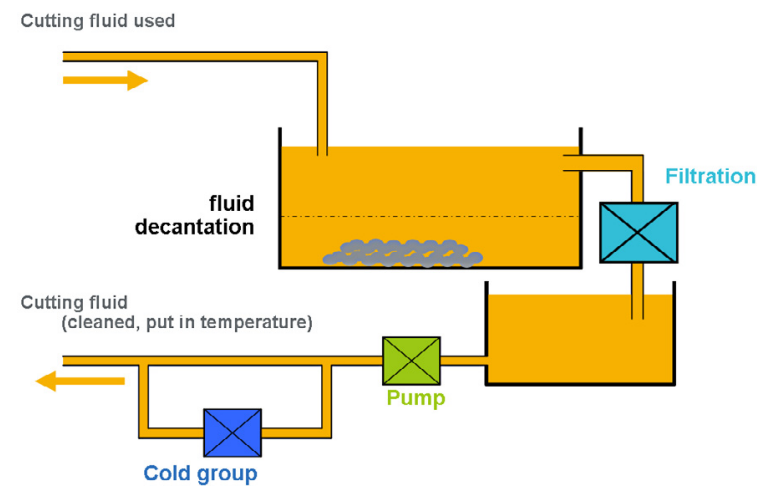

Fig. 9. Principle of functioning of the power plant of lubrication studied.

of cutting and the machine) and maintain in a mastered temperature part, tool and machining centre [1].

Volume of cutting fluid having circulated to make a part is measured by means of the use of a volumeter placed in entrance of the machining centre. For a part, the volume of fluid having circulated in the machine is $1.1 \mathrm{~m}^{3}$, the flow of cutting fluid is thus about $10 \mathrm{~m}^{3}$ per hour and by machine in functioning. We shall note that this volume of circulated cutting fluid is very dependent on the used machining centre: it depends on the size of the zone of manufacturing and on the number of exits of cutting fluid.

\section{Measures realized on the power plant of lubrication}

\subsection{Principle of functioning of the power plant of lubrication}

The distribution of the cutting fluid (mixture of water and cutting oil in $7 \%$ of concentration) in the factory is centralized. The cutting fluid useful for our manufacturing results from a power plant feeding 45 machine of identical manufacturing and producing all clutch or transmission case similar. This power plant works on the principle described by Figure 9 .

Consumption in water and in cutting oil was followed during the eight first months of year 2010. The spending of energy connected to this lubrication plant was estimated by means of measures realized on equivalent lubrication plant in the other factories of the group Renault.

\subsection{Addition of cutting fluid}

Circulation of the fluid in the machine, on the part but also in the entire factory cause losses. These losses are connected to the evaporation, to the diverse leaks (pipe, machine, lubrication plant) as well as in the residues of liquid left on the part at the end of manufacturing.

The follow-up of the additions of liquid in the power plant is presented in Table 1 . The presented data are extrapolated for one year from the available figures for seven
Table 1. Annual consumption of oil and water in the plant.

\begin{tabular}{cccc}
\hline & Water & Oil & Total \\
\hline Annual & 1695 & 53 & 1748 \\
consumption & $\mathrm{m}^{3}$ & $\mathrm{~m}^{3}$ & $\mathrm{~m}^{3}$ \\
\hline Consumption & 1500 & 45 & 1545 \\
by part & $\mathrm{mL} / \mathrm{part}$ & $\mathrm{mL} / \mathrm{part}$ & $\mathrm{mL} / \mathrm{part}$ \\
\hline
\end{tabular}

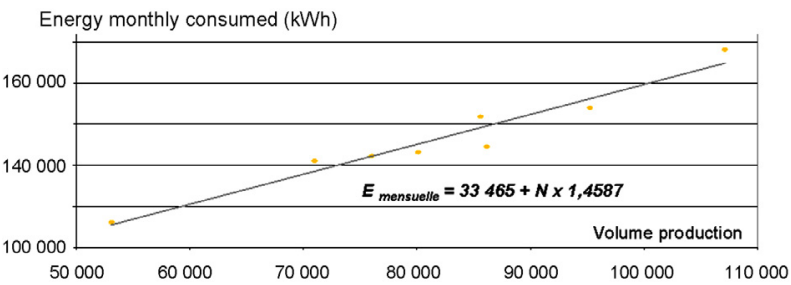

Fig. 10. Monthly energy consumption of the lubrication plant according to the number of produced part.

first months of 2010. This table shows that for every produced clutch case, 1 and a half liter of water and $45 \mathrm{~mL}$ of oil are lost.

\subsection{Electrical energy}

The electric consumption of the lubrication plant is bound to two elements: the cold group (which role is to maintain in a 20 temperature ${ }^{\circ} \mathrm{C}$ (in $1{ }^{\circ} \mathrm{C}$ near) the cutting fluid and for pumps asked to make circulate permanently the liquid in the network of the factory. Indeed, to avoid the pollution of the mixture by mushrooms and bacteria, it is impossible to let rest the cutting fluid in the lubrication plant or the piping of the factory.

Figure 10 presents the monthly energy consumption of a lubrication plant comparable to that used in the factory studied according to the number of produced clutch cases. We notice that the energy consumption is proportional among produced parts.

We can thus decompose this energy as a part connected to the circulation of the fluid in the machining centre and a part connected to the circulation of the fluid in the factory.

In the balance sheet, the studied data shows that to make circulate and maintain in temperature the cutting fluid, it is necessary to spend an energy about $1.76 \mathrm{~kW} . \mathrm{h} /$ part.

\section{Synthesis}

\subsection{Electrical energy consumption}

Table 2 presents the synthesis of the electrical energy necessary for the production of a clutch case.

Analysis of Table 2 reveals that the machining centre consumes less half of the electrical energy necessary for the production of a clutch case. The biggest energyconsuming is the lubrication plant. 
Table 2. Synthesis of energy consumptions necessary for the production of a clutch case.

\begin{tabular}{ccccccccc}
\hline & \multicolumn{9}{c}{ Machining centre } & \multicolumn{3}{c}{ Compressed } & Cutting \\
& HP pump & Air conditionning & Pump AC. & Spindle & Others & air & fluid \\
\hline $\begin{array}{c}\text { Energy } \\
\text { (KW.h) }\end{array}$ & 0.21 & 0.18 & & 0.4 & 0.36 & 0.36 & 0.23 & 1.76 \\
Total & & & 1.52 & & & & & \\
\hline
\end{tabular}

By being interested in all the elements necessities in the watering of the part, we realize that this part takes up to more than $55 \%$. The consumption of the spindle (that is of the element serving directly to remove some material) represents approximately $10 \%$ of the global consumption of this machining centre, for the production of this type of clutch case.

\subsection{Water consumption}

As we saw it higher, the manufacturing of a clutch case consumes about $1.5 \mathrm{~L}$ of water. On the scale of the production of the factory of Cléon (production of 1 million of transmission a year) this consumption represents $3000 \mathrm{~m}^{3}$ of the water (that is the equivalent of the volume of an Olympic swimming pool). We shall note that the factory also produces cylinders blocks, cylinders heads, camshafts, crankshafts, conrods and wheels for transmission. Every year the factory consumes approximately one million $\mathrm{m}^{3}$ of water.

\section{Conclusion and perspectives}

The study presented here allowed to quantify the energy necessary for the production of a clutch case. We were not interested in the energies connected to the secondary functions of the factory (lighting, heating, ... ) as well as in the energy consumption bound in unproductive time of the machine (wait, put in temperature of the machine, ...) but only in the energy directly consumed by the manufacturing of the clutch case. The reduction of the energy consumption in these phases of life of the machining centre also represents an important source of earnings of energy. It is a point more and more advanced by the manufacturers of machines.

This study thus brings to light the part of consummate energy bound to the watering of the part and thus to the cutting fluid (economic and ecological impact).

On the other hand, as we saw it, the manufacturing of a clutch case is strongly consumer of water (ecological impact).

Finally a study of the BIA quoted by Zielasko [2] brought to light the impact of the cutting fluid on the health of the operators working in the metallurgical industry. Indeed, this report teaches us that a quarter of operator's pathologies met in the metallurgy industry are dermatological problems. This report considers that a third of these dermatological problems would be directly connected to the use of cutting fluids in manufacturing.
A way of reduction of these consumptions (energy and water) can be the use of the technology of manufacturing with quantity of lubricant minimal (MQL, minimum quantity lubrication) [3-5]. This technology suggests replacing the watering of the part inside the machine by the pulverizing of a mixture air and oils only in the zones of chips formation. It would thus allow to reduce the consumption of oil, to eliminate the water consumption as well as the energy consumption of the lubrication plant. However, this technology imposes to find solutions of the problems connected to the abolition of the watering: evacuation of chips, preservation of the temperature of the part and of the machining centre... Moreover this technology increases the consumption of compressed air necessary for the manufacturing of a part.

This study allowed us to establish an inventory of fixtures of the energy consumption and the cutting fluid necessary for the manufacturing of an aluminum clutch case with watering of cutting fluid. The next stage could be to try to compare the energy consumption necessary for the production of the same part by using a machine tool equipped with MQL. This study would allow to end on the interest, from an energy point of view of the replacement of the lubrication by watering by a lubrication with minimal quantity of oil.

Acknowledgements. Results presented above were obtained within the framework of a project supported by the "Agence de l'Environnement et de la Maîtrise de l'Énergie" (ADEME, France).

\section{References}

[1] B. Broquerie, Fluides de coupe : Rôle en usinage et classification, Techniques de l'ingénieur, Génie mécanique (2001) BT1, BM7064 BM7064.1-BM7064.13

[2] W. Zielasko, M Zimmermann, Machining with MQL: what users expect from machine tool manufacturer 2004

[3] K. Weinert, I. Inasaki, J.W. Sutherland, T. Wakabayashi, Dry machining and minimum quantity lubrication, CIRP Annals-Manufacturing Technology 53 (2004) $511-537$

[4] M. Lahres, P. Muller-Hummel, O. Doerfel, Applicability of different hard coatings in dry milling aluminum alloys, Surface and Coatings Technology 91 (1997) 116-121

[5] S. Suda, H. Yokota, I. Inasaki, T. Wakabayashi, A synthetic ester as an optimal cutting fluid for minimal quantity lubrication machining, CIRP Annals-Manufacturing Technology 51 (2002) 95-98 